\title{
Traffic Patterns
}

By KEYES D. METCALF

LIBRARY BUILDINGS are designed to be used, and use obviously implies traffic. One of the essential characteristics of a functional building is accessibility with a minimum of effort and minimum of disturbance. If planning is to produce satisfactory traffic patterns, it must take into account problems of supervision and control of the building and its exits, facilities for communication and vertical transportation, and means of minimizing noise and other distractions. Spatial relationships are also involved, but these cannot be considered in this article.

\section{SupERVISION AND CoNTROL}

Most librarians would rather help than supervise those who use their buildings; they have no desire to act as police officers, and are eager to make controls as inconspicuous as possible if they cannot be eliminated. It is good to be able to add that less supervision is required now than was thought to be necessary a generation ago. Today's students, both graduates and undergraduates, seem to be more serious than their predecessors and come to the library to study rather than for social purposes. Better acoustic materials have reduced the disturbance that results from whispering and talking. Many libraries now admit students to the stacks, where close supervision is almost impossible; consequently it is hard to justify intensive supervision of reading rooms. At least three out of four students prefer individual seating, and seating of this kind, which is being provided more and more generously, discourages conversation in reading areas and hence reduces the need for supervision. Better traffic patterns and seating layouts which reduce noise and confusion help to cre-
Mr. Metcalf is Librarian Emeritus, Harvard College library.

ate an atmosphere conducive to orderly behavior. Finally, there is a growing realization that the most economical and, in many ways, the most satisfactory location for supervision and control is at a building's exit or exits.

It should be emphasized that no one advocates control, even at exits, if it can be eliminated without serious consequences. Unfortunately, as students grow increasingly serious and need less supervision within the building, they seem to be tempted more and more to appropriate library materials extralegally; the problem is particularly serious in the case of reserved books. Attendants at the exits can not search everyone who leaves the building; books can be concealed in clothing, particularly during the winter. Experience indicates, however, that, if it is known that unauthorized borrowing is a serious offense punishable by dismissal or suspension, inspection at the exits can be more effective than the traditional method of reading-room supervision. Most new buildings provide either for control at the exits or for no control at all.

Control at the exits is no safeguard against theft of rare books by professional thieves; the only satisfactory procedure is to keep very valuable materials in closed stacks, supervise their use by persons who have signed for them, and check them in immediately on their return, before the reader leaves, in order to make sure that they have not been mutilated. Exit controls can be expected, however, to prevent unauthorized borrowing by absent-minded students and 
professors and to deter deliberate theft because, if an individual must conceal a book to get it past the controls, he can hardly pretend to himself or, if apprehended, to others that he has taken it thoughtlessly, rather than deliberately.

It may be suggested also that though controls may not seem necessary at the time a building is planned, conditions may change. It is desirable, therefore, to plan the building so that exit controls can be provided at some later date without expensive alterations and without ruining the appearance of lobbies.

Various methods of exit control are possible. Turnstiles were used for some years in the Widener library at Harvard and have been used at the New York Public Library for a long period. It should be noted that persons entering a building may also be required to pass through turnstiles, as at Princeton's Firestone library. Either electric eyes or turnstiles can be used to count those who enter, though neither can be relied upon for a completely accurate count.

Chains or railings of some kind can be used to channel readers through a narrow lane past a desk. At the Lamont library as many as four exit lanes can be opened at one time in the main entrance, and two in the secondary entrance, but only half of these have proved to be necessary in order to handle the traffic without forcing students to line up.

A third method, which has been used in the Widener library since the unattractive turnstiles were removed, is to leave a passage more than six feet wide with a counter on the right-hand side behind which an attendant sits on a high stool. This has proved to be reasonably satisfactory at Widener, where much of the use is by professors and graduate students. In an undergraduate library, where there is very heavy traffic just before each class period begins, narrow passages seem to be preferable.
Mr. Metcalf is engaged in preparing $a$ book on the planning of college, university, and research library buildings. "Traffic Patterns" is the preliminary version of a chapter from that volume which CRL is pleased to publish here as the fifth of a series of excerpts from it.

Mr. Metcalf invites suggestions and comments for consideration for use in the final version of his work.

The research for his book and the writing of it is being done by $\mathrm{Mr}$. Metcalf as the director of a special project sponsored by a grant from the Council on Library Resources (CRL, XI (1960), 136).

Control counters may also serve as information desks where the stranger can obtain directions, which are often needed in any large library. Counters rather than desks are suggested, because it is not convenient for readers to show books on a low surface; a height of forty-two or even forty-three inches is preferable to thirty-nine, and the increased height makes possible a reduction in width. For use when he is not standing, the attendant should be provided with a high stool having a back and a footrest or a platform in the kneehole of the counter. It should be possible for the attendant to reach the outside door quickly if necessary, but it is preferable that this feature be inconspicuous.

In some cases it is possible to install a long control desk at the exit that serves also as the main circulation desk and even as the desk for service of books on closed reserve. If this is possible there are significant advantages. The noise and confusion that circulation services always entail is confined to the entrance lobby; the number of staff members who must be on duty during quiet periods is reduced, which may be an important financial consideration; and the reader may avoid having his books checked twice, once when he signs for them and again when he leaves the building. 
Nothing has been said thus far of how many entrances and exits may be needed. Most libraries, of course, must have a separate shipping and receiving entrance, which may be available for use by members of the staff. Each public entrance and exit is expensive; attendants must be paid and floor space must be provided in the building plans. Moreover, the whole traffic problem within the building can be simplified if there is a single entrance and exit. In a large library, however, traffic is often so heavy and distances so great that a second entrance and exit is essential. Fire laws may require it; if they do not, emergency exits with crash locks should be available.

Control of each additional exit may require payment of two or three additional salaries in a library that is open for seventy-five to one hundred or more hours per week. Moreover, a secondary exit will normally be used considerably less than the main one, and may not be a suitable place for circulation or reserved-book services. There may be a problem in keeping the attendant profitably occupied. In the Lamont library at Harvard a portion of the reserved-book collection is kept behind the desk at the secondary entrance, which is on a different floor level from the main entrance. Those using the bottom level of the building need not climb an additional seventeen feet if they come in at the side entrance, and division of the traffic load is desirable. It can be noted also that traffic is so heavy that two checking-out posts would be needed most of the time at the main entrance if it were the only one.

In the Widener library also the second entrance is on a different level from the front door, and controls a secondary entrance to the book stack, which is a great convenience in a ten-level stack. Fire regulations require that two exits be provided in each building at all times when it is open; elsewhere, however, there are equally large buildings operating under regulations that call for emergency exits only. These can be controlled by glass that must be broken to open the door. An exit of this sort at Princeton has been the victim of unauthorized use only once in fifteen years.

Glass can be broken, of course, and a thief or errant student can escape unless there is an effective alarm system. If the exit door is at the end of a fairly long corridor, an alarm may sound at the other end of this corridor, at the nearest service desk, and perhaps in the janitor's quarters. If the library is near a main gate to the campus where an attendant is on duty at all times, an alarm may ring in his station.

A discussion of problems of control and supervision would be incomplete if it did not mention the difficulties that sometimes occur when there are outdoor reading terraces. These can be attractive and some architects delight in them, but their disadvantages ought not to be overlooked. Books can be dropped from them to a waiting confederate or to the ground if a secluded spot is available. Dust and air pollution may make them unsatisfactory places to read and, in most sections of the country, the number of dry and warm days when they can be used is discouragingly small.

Entrances and exits are where traffic patterns begin and end. The decisions that are made regarding them also affect the security of the library's collections and its operating costs. It is important, therefore, that entrance lobbies be designed with a view to installation of control desks in the future if not at once, with space for rush-hour traffic and provision for channeling those who are leaving past a desk.

\section{COMMUNICATION AND VeRTICAL TRANSPORTATION}

Unless a library is very small, mechanical devices for communication will 
probably be needed. Unless the whole library is on a single level books and people will have to move from one floor to another. To consider communication and vertical transportation is to consider stairs, ramps, booklifts, conveyor belts, escalators, elevators, telephones, public-address systems, telautographs, and teletypes. The uses of these varied devices will be discussed as a means of helping the librarian to decide what is needed and of indicating something of library requirements to architects and engineers.

The number of stairways that is desirable will depend, of course, on the amount of traffic, the size of floor levels, and, to some extent, the total squarefootage of the building; local building regulations and fire codes may also impose specific requirements. They often state that no place in a building shall be more than a certain number of feetsometimes the figure is one hundredfrom a stairway providing direct access to an exit from the building. The codes often permit only one open stairwayi.e., only one outside a fireproof enclosure with closed doors at each level. They may also permit the open stairway to connect only two levels; in this case it may be open from the first to the second floor, but if the same stairway continues down to a basement or up to a third floor, it must be enclosed at these levels.

Some buildings do not come under code restrictions, either because there is no applicable state law or local regulation or because the institution is exempted; sometimes a limited exemption can be obtained if sprinkler systems are installed. Fire risks will not be discussed here, but it should be emphasized that no building should be planned without checking the codes and regulations to which it must conform.

Architects may recommend that open stairways, often monumental ones, rise from the main floor as an architectural and aesthetic feature. A monumental stairway in a small library may be out of proportion, but it can be attractive as well as functional in a large building. Contemporary fashion favors stairways as light and seemingly insubstantial as possible, apparently hanging in air and completely open except for hand railings to prevent accidents. The University of Miami library at Coral Gables has a stairway of this kind.

The location of both main and subsidiary stairways is important; indeed, it is usually a primary factor in determining floor layouts. They should be convenient for use, and reasonably conspicuous if students are to find them readily and use them instead of looking for mechanical transportation; on the other hand, they should not be allowed to obstruct the major traffic arteries on each floor.

Stairways are often placed in a central building core, together with elevator shafts, toilets, and other fixed services, leaving the remainder of the building as flexible and adaptable as possible. This plan also reduces the extent of the interior walls that will be required. Another possibility is to place the main stairway immediately adjacent to the main entrance and next to an outside wall, leaving the rest of the building unobstructed by a permanent installation. As has been noted, however, fire laws usually necessitate at least one secondary stairway, and large buildings require more than this; in some cases a stairway in each corner may be desirable in addition to the central stairway.

Decisions on the steepness of stairs involve questions of design, comfort, and the use of space. If the ascent is too gradual, space will be wasted and many persons will find it awkward to climb. If stairs are too steep, many persons will find them difficult to climb. In general, the most acceptable height for risers 
is no more than seven and one-half inches, and risers of less than six or more than eight inches should be avoided. The following simple formula is often used:

1. The product of the riser and the tread should be between seventy and seventy-five.

2. The risers plus the tread should be from seventeen to seventeen and onehalf inches.

3. The sum of the tread plus twice the riser should be between twenty and twenty-five inches. ${ }^{1}$

Decisions on stair widths depend primarily on the traffic expected at times of peak load. Indeed, many decisions in library planning must be based on anticipated peak loads, and, particularly in academic institutions, these normally come when classes change. Emergencies such as fire should also be kept in mind; in times of emergency, traffic can be expected to move in a single direction, making the full width available. Building codes often stipulate the minimum width as well as the maximum width permissible without a railing down the center. Eight feet is often set as the maximum between railings. The minimum for floor-to-floor stairs is usually three and one-half feet clear between rails, though narrower stack stairs are often considered adequate. The legal width may depend upon the number of occupants on the other floors served.

If a stairway is to be a fire exit, it must lead as directly as possible to an outside door, and this door must always be made to open without a key from the inside during periods when the building is open to the public. All library stairways should have hand railings, ordinarily thirty to thirty-two inches above the intersection of the tread and riser at the front end of the steps. This will bring the railing to from two feet ten inches to three feet above the floor at

${ }^{1}$ Frederick S. Merritt, ed, Building Construction Handbook (New York: McGraw Hill, 1958). landings. Some architects recommend heights as much as six inches greater than these. A railing that goes a short distance beyond the bottom step will help those who are handicapped, but must be so installed that it is not a hazard for normal persons rounding the corner to go up the stairs.

Architects sometimes propose circular stairs because of their aesthetic advantages, but they are to be avoided in most cases. If the narrow edge of the circular stair tread is to be wide enough to be reasonably safe, considerable space must be left in the center; legal requirements often set a minimum. The total squarefootage of floor space required by an adequate circular stair well is considerably greater than would be needed for a direct stairway or for one going around one, two, three, or even four corners, particularly if it is considered that the space immediately outside the circle is usually useless for library purposes. If a circular stairway is to be installed in spite of these disadvantages, it should be so designed, in countries where pedestrians normally keep to the right, that the person going upstairs on the right uses the narrow end of the tread; this will reduce to some extent the dangers presented by any nonrectangular stair tread. Likewise, of course, where pedestrians keep to the left, a stairway rising counterclockwise is indicated. Few architects, it appears, have taken this principle into account.

Apropos of stairways and safety, one further warning may be offered: Avoid like the plague a flight of only two steps; a single step is worse yet. In some places it is illegal to offend in this way, but it is hard to excuse the infraction whether it is an offense against the law or only against common sense. If a library is afflicted with such stairs, they should be properly marked and lighted; in some cases it may be possible to replace them by ramps as was done in the Widener 
building at Harvard, where accidents had occurred, on the average, once a week for forty years. Obviously it should be possible to move books by truck throughout a library building with a minimum of trouble, yet architects of earlier days sometimes placed short flights of steps at a variety of points in a building. The old library at Cornell, now completely rehabilitated as the Uris undergraduate library, was an example.

It has been noted that the substitution of ramps for stairs helped to improve the Widener building. Steep ramps are to be avoided if book trucks must traverse them, and any slope greater than 5 per cent will be difficult for a person on crutches. A 5 per cent incline entails eighty feet of ramp for only four feet in altitude; a 10 per cent gradient would take only half this space for the same rise, and 10 per cent should be the limit even for very short ramps. A nonskid surface is essential on all ramps, and hand rails should usually be provided. If a change in level is required at the approach to a staff elevator, a ramp is to be preferred to stairs, but the change in level should be avoided altogether if possible. A ramp may be the lesser evil when an addition is made to an old library and it is impossible to make floor levels match.

Escalators, which can handle a large volume of traffic and use relatively little power, can be useful in some cases. They function continually without requiring an operator. It is doubtful, however, that any library can afford to install them between as many as four levels, and it seems out of the question to go beyond that. For heavy traffic between only two levels they may be both useful and economical, as in the new Columbia Law School library, where every reader must go up one floor to reach the library. In the University of Miami library at Coral Gables escalators go from the first to the third floor, with three separate lifts, as two were used between the first and second floors. These escalators go up only, so they cost only half as much and require only half as much space as if they went both up and down. It is estimated at Coral Gables that, though only of medium width, these escalators have a greater capacity than four elevators, and cost less for space, installation, and operation; it is doubtful, however, that four elevators would have been necessary.

The location of escalators calls for careful consideration, and each end should be located where it will not obstruct traffic. Particular care is indicated if more than two levels are involved. It is also essential that escalators be very carefully installed; they must be tailormade for the building if they are not to be unduly noisy. Special fire protection devices may also be required.

Book lifts, sometimes called dumbwaiters, vary widely in size; some are only large enough to hold a folio volume; others will take a loaded book truck. A few book lifts survive that must be operated manually by pulling a rope, but electric power and push-button controls now prevail. One disadvantage of any book lift is that, if there is no staff member at the level to which the lift is sent, the person who loads the lift must climb up or down stairs to unload it. Even in a large library, where an attendant is stationed at each level, confusion may result if the attendant is temporarily absent from his post. If the lift is too small to handle a truck, its use almost inevitably involves at least one or two extra handlings of each book transported. Many libraries rarely use the book lifts they have.

Wear and tear in handling is not an important consideration. Pages, particularly when working under pressure, are inclined to throw books into a lift. For many years thousands of books, sometimes five thousand a day, at the New 
York Public library were transported between the stacks and the main reading room by book lift, and the resultant damage to bindings was serious. Yet, if an elevator is beyond the library's means, a book lift, particularly if large enough to carry a truck, may be better than nothing. Building codes may require fire-resistant shafts, and insurance rates may be affected. If the lift is to carry a book truck, it must, of course, open at floor level on each floor.

Elevators are clearly preferable to book lifts in every respect but one-they are more expensive. Their cost, in a small library, may represent a substantial fraction of the total expenditure for construction. The cost will be affected by several factors. Is the elevator propelled by cables or by water- or oil-driven pistons? What is the size of the cab? What is the maximum weight to be carried? What is the total length of the rise? What speed is required? How complex are the controls required in order to provide service without an operator? Is there to be an accurate leveling device?

Electrically operated cables are always used in high buildings and often in others. Elevators propelled by a wateror oil-driven piston are less expensive to install and operate when a lift of fifty feet or less is required. They are relatively slow, but may well be considered for freight, and, occasionally, for public use.

The machinery for electrically operated cable elevators is usually located in a penthouse rather than in the basement; this saves in costs of installation and operation, reduces wear and tear on the machinery, and helps to minimize noise enough to obviate special acoustic treatment. When heavy loads are to be handled and speed is not important, what is known as two-to-one roping is used instead of one-to-one.

The number of passenger-elevator cabs that will be needed depends on the volume of traffic and the waiting period that will be tolerated, the capacity of the cabs, and their speed. Traffic customarily is measured by the number of persons to be transported in a five-minute peak-load period, and there are standard formulas that can be used. These take into account the time required for a full-speed round trip without stops, plus time for accelerating and slowing down at each stop, time for leveling at each stop, time for opening and closing gates and doors, time for passengers to move in and out, lost time resulting from false stops, standing time at top and bottom floors, and reaction time of the operator if there is one. The wider the doors, the more rapidly passengers can move in and out. Doors that open at the center speed up operation to some extent.

If wages are to be saved by eliminating operators, automatic elevators must be installed. These are of three principal types. The simplest responds to the first button pushed and does not "remember" any other calls. The selective-collective type answers only calls in the direction in which the car is moving. Finally, a fully automatic system can be adjusted to operate in a variety of ways designed to suit traffic demands of different levels and types depending upon the time of day. The more complicated the controls, the more they cost. Small libraries are rarely justified in installing anything but the simplest type. Safety devices, however, should always be used to prevent the car from moving when doors are open. Car speed should be increased in high buildings.

Two elevators in one bank will carry more traffic without undue delay than three widely separated ones, and three together in a large building will probably be as satisfactory as five or six widely separated elevators. In the Widener library, where there are five auto- 
matic elevators, each something like 125 feet from the others, it is often necessary to wait five minutes or more for a car. Three elevators in a single bank would give better service, though passengers on the average would have to walk greater distances to reach them.

A major question in locating elevators is whether or not to place them in a part of the building not open to the general public. Traffic will be heavy if they are used by undergraduates going up or down only one or two floors. Use can be restricted by having elevator doors and call buttons operate only by key, and distributing keys only to members of the staff and physically handicapped readers. Another possibility is to locate elevators behind a desk where an attendant is always on duty. Control has been facilitated in several new buildings where the bank of elevators is at the rear of the circulation desk lobby or in the central core of the building. If stairways leading to restricted levels are also located in this space, there are considerable advantages. Control, it should be emphasized, may be needed for two purposes - to restrict stack access to professors, librarians, and graduate students, and to relieve the load on elevators, which are very expensive to duplicate.

The gravity of the problem will be recognized by anyone who has waited fifteen minutes for an elevator in the University of Pittsburgh's cathedral of learning, as well as by anyone who has helped to plan an eighteen-story library building in which it will cost $\$ 500,000$ to provide six elevators for passengers and one for freight. It should be added that, when an automatic elevator is pushed too hard by heavy traffic, its nervous system is likely to break down, and remedial treatment is costly.

One means of reducing the load on elevators is to confine the library's most heavily used facilities to the entrance level and the levels immediately above and below, which readers can be ex- pected to reach by stairways. If this can be done, it will be much easier to provide satisfactory elevator service for the professors and graduate students who use the library even more intensively than undergraduates but do not rush in and out in such large numbers between classes.

A leveling device is of great importance, particularly if elevators are used for transportation of heavily laden book trucks. Without such a device, it is difficult for even a skilled operator to stop a car in exactly the right place, and a loaded truck going up or down even an inch as it enters or leaves an elevator is subjected to more wear and tear in a few seconds than during days of operation on the level. The books it contains are also likely to fall off.

If the reader is inclined to think that questions of cab size and elevator speed, or the number of cars and their location are minor matters, he is urged to reflect that an elevator in a five-level building will cost $\$ 35,000$ in addition to the space occupied by its shaft and by the lobby in front of it. This is an investment large enough to warrant careful consideration.

Conveyors should be considered if there is a fairly continuous flow of books or other library materials through a multi-tier building. They may provide a more satisfactory solution than either book lifts or passenger elevators. An endless-belt conveyor is similar mechanically to an escalator, but it goes straight up and down. Like elevators, conveyors should be enclosed in fire-resistant shafts. Attached, usually at approximately ninefoot intervals, to the chains that go up and down are carrier prongs on which books can be placed as the prongs go past. It is desirable to provide light trays in which the books can be placed; otherwise, there is danger of books falling down the shaft. The books or trays laden with books can be placed on the conveyor at any level. They then go to 
the level that has been indicated by pushing a button when they were loaded. If this level is below their starting point, they first go to the top, swing around, and then come down.

It should be noted that the simplest conveyor installations have proved to be the most satisfactory; those that pick up material at any level but deposit it at only one-e.g., the reading-room levelare least likely to get out of order. Two conveyors of this sort have been in operation at the New York Public library for nearly forty years with very few difficulties. More complicated types are to be found at Yale and in the old Library of Congress building, where, because the stack is not directly above, below, or adjacent to the charging desk or reading room, the conveyors have to travel horizontally for a considerable distance. A central location for conveyors is highly desirable, of course. Installation by a stair well is advantageous because it may facilitate access for servicing and repair. Precautions should be taken to make conveyors as quiet as possible; many have caused trouble by creaking and groaning.

Pneumatic tubes have been used for many years to transfer call slips from circulation desks to attendants in the stacks. Propulsion is by air pressure, and slips can be delivered much more rapidly than by elevator or conveyor. Many new charging systems, however, use punched cards of one kind or another for call slips, and these cards, which should not be bent, cannot readily be inserted in the pneumatic tube containers that have been used heretofore.

Much larger pneumatic tubes have been used for transporting books over considerable distances when vertical or horizontal endless-belt conveyors do not seem to be practicable. The connection between the Library of Congress Annex and the main building is an example; containers used there are approximately a foot in diameter and eighteen inches in length. The difficulty is that they stop at their destination with an abrupt jar, and books are likely to be damaged unless they have been tightly strapped in place; moreover, of course, to strap the books tightly does them no good. Hence, there is a real question as to whether or not pneumatic tubes for transportation of books can ever be entirely satisfactory, in spite of the great advantages in speed that they offer over long horizontal distances. When the final section of the Australian National Library has been constructed, books may have to travel as much as five hundred feet horizontally before they reach vertical conveyors to bring them up to readers. If they move at a rate of eighty feet per minute, which is approximately the maximum safe speed for an endless-belt conveyor, it will take them seven minutes to reach the transfer point, and the total time from stack attendant to readingroom desk will be about nine minutesthis, of course, after the time that has been taken for the call slip to reach the stacks and for the attendant to find the book and place it in the conveyor.

Telephones are essential in any college or university library. The large library may have its own central switchboard, or house the switchboard for its college or university. It is important to facilitate communication within the library, and money may be saved if any instrument in the building can be connected with any other there without going through an outside switchboard.

Decisions must be reached on how many telephones are needed, and how many of these can be extensions without a separate main line to the outside. Location of telephones is an important matter. Unauthorized calls can be expensive-directly, in the case of toll calls, and indirectly when they waste the time of employees. Faculty members have also been known to take advantage of unsupervised instruments in order to make 
long distance calls free of charge. Except for telephones in private offices, therefore, each instrument in the library ought to be placed where a responsible member of the staff can see and hear how it is being used. If one is located at a desk that is in use only part of the day, it should be safeguarded against misuse at other times, either by locking the dial or arranging for it to be cut off by the switchboard.

In planning the conduits for wiring that are to be installed at the time the building is constructed, it should be remembered that installation at any later date will be much more expensive. Both extensions and regular stations are costly and should not be provided before they are needed, but it is uneconomical in the long run not to install at the outset all the outlets that will eventually be wanted.

Pay telephones are usually desirable in a library, and the telephone company will gladly install as many of them as promise to be profitable. In some cases the library receives a commission on receipts, but it may be worth while to provide pay telephones even if the institution must make up a small deficit in order to have them. They should be located where they will not disturb readers, which usually suggests a hallway or lobby, though preferably not too secluded a place.

Other means of communication are to be found in a few large libraries. The telautograph, which may be observed in some railway terminals, enables a person to write by hand a message that is reproduced elsewhere in the same form, but it is awkward enough to interfere with legibility, and few libraries have found it useful. Teletype, by which a typewritten message is made available in the same form at the other end of the line, has been used at the Midwest InterLibrary Center, the Library of Congress, and elsewhere. It is expensive, particu- larly for intercity communication, and should not be considered unless heavy and important traffic is anticipated; for less frequent communication, long distance telephone, or commercial telegraph is cheaper.

Loudspeaker and public-address systems, as well as two-way radio installations (as in taxi-dispatching systems) have been used in some libraries, particularly for direct communication between the circulation desk and stack attendants. Care should be taken to avoid creating a disturbance either at the desk or in the stack, especially if the stack is one to which readers are admitted. In a research library, complications may arise from communications relating to materials in foreign languages with which members of the staff are unfamiliar.

Large libraries, particularly those with open stacks, may also find it difficult to notify readers of closing time in order to clear the building. Warning gongs or public address systems may be useful. In planning stack layouts it should not be forgotten that it will be necessary to make sure that all readers have left before the building is closed.

\section{Noise and Other Distractions}

Noise has been mentioned at various points in the preceding discussions of supervision and control and of communications and vertical transportation, but noise and other distractions are not incidental matters; they fully deserve to be considered as fundamental problems in any survey of traffic patterns. Soundabsorbing materials can do much to minimize noise, but it is better to prevent noise rather than try to absorb it. Visual distractions are a closely related subject.

It should be conceded that there are fortunate individuals for whom noise and motion are no problem; those who have grown up amidst large families or have worked from an early age in large open offices may be nearly immune to 
distractions. Many undergraduates, however, are not immune, and undergraduates may deserve particular consideration in this respect. The professor can usually find a secluded corner in his own home even if he does not have a private study in the library. The graduate student in many institutions is now provided with a reasonably quiet and secluded cubicle or carrel. But for the younger student, the only alternative to a library reading room may be his own dormitory, where his roommate may operate on a different timetable and gregarious friends may be plentiful. The reading room is likely to be crowded with his contemporaries, and table space available to him there may be no more than thirty inches wide by eighteen inches deep, which is not enough for spreading out books or, indeed, for opening more than one if space for taking notes is also needed. The chair may be unsatisfactory; its arms may be designed for comfort, but a needlessly deep apron beneath the table may prevent the chair from being drawn close. In one large college library two out of three readers must straddle chair legs within a few inches of the edges of the tables. Lighting may leave something to be desired.

Fully as serious as any of the handicaps that have been suggested is the fact that the reading room may be in almost constant turmoil. It may settle down twenty minutes after a class period begins, only to be disrupted again fifteen minutes before the period ends as students begin to leave. Afternoons and evenings may be disturbed by more continual, though less concentrated, coming and going. In many ways the contemporary undergraduate may be worse off than his predecessors; the great monumental reading rooms of earlier days absorbed noise and tended to engulf the reader just as a large stadium filled with cheering crowd may leave the athlete oblivious of everything but his immediate surroundings.
The new, more intimate reading rooms, continue to be surrounded by shelves holding heavily-used reference books that attract steady traffic. Entrance to the room is often through a single doorway in the center of the long side or, worse still, at one end; few readers can enter or leave without going past many tables at which others are attempting to study.

The foregoing account of the undergraduate's woes may be enough to indicate why the following principles need to be emphasized:

1. Noise and confusion should be kept out of reading areas in so far as possible. Circulation and reference desks should be elsewhere, with books, walls, distance, or acoustic materials - perhaps more than one of these barriers-to separate them from readers. The public catalog and, to a lesser extent, shelves holding reference collections are also areas of relatively heavy traffic. Use of current periodicals involves a good deal of motion. If periodicals or reference books must be in the reading room, they should at least be placed at one side or one end, with adequate acoustic insulation.

2. Access to reading areas should be provided through as many well distributed entrances as possible. If the student can usually find a seat near the point at which he enters the room, he can be expected to leave the same way, and both visual and auditory disturbance can be kept to a minimum.

3. Individual seating accommodations are highly desirable. They will be most satisfactory if a barrier at the back of each individual table can be built up to a height of fifty-two to fifty-four inches, which is enough to prevent the reader from seeing the head of the person in front of him. In a seat of this kind he should be able to turn slightly away from the rest of the room and obtain visual privacy if he wishes.

4. Table surfaces should be large 
enough to permit the student to spread out the materials on which he is working. Space on an individual table goes farther than space on a large table; a surface measuring twenty-two by thirtythree inches is as useful in an individual table as a segment measuring twentyfour by thirty-six on a table that must be shared.

5. Noise and other distractions should be kept in mind when planning traffic lanes throughout the building. Stairs in the vicinity of reading areas should be well sealed off. Elevators, which are also noisy, are a similar problem, and elevator lobbies must be separated from reading areas.

6. A plan designed to avoid disturb- ing readers should not make a maze of the library. Devious and complicated traffic lanes will discourage use of the building and cause frustration and wasted time.

7. Traffic patterns in book stacks also vitally affect the welfare of readers. The tendency is to locate a larger and larger percentage of total reading accommodations in the stacks. It is important to avoid main traffic arteries that go past open carrels along a wall.

These are obvious principles, but few libraries have not disregarded one or more of them. Good traffic patterns, plus adequate lighting and ventilation, are essential if the library is to be a satisfactory place for study.

\section{Library Buildings Awards}

\section{Program Announced}

A cooperative "Library Buildings Award Program" to encourage excellence in the architectural design and planning of libraries has just been announced by the American Institute of Architects, ALA, and the National Book Committee. Any library in the United States completed after January 1, 1958, and designed by a registered architect practicing professionally in the United States is eligible.

A jury, appointed by the American Institute of Architects, will include three architects, and one representative each of the American Library Association and the National Book Committee. To insure adequate library representation, three librarians to represent each class of libraries are to be named, each of whom shall serve only when his classification or category is being judged.

Entries will not be judged in competition with other entries, but on the basis of the solution of the problem presented to the architect and its worthiness for an award for excellence in library architecture and planning. The jury will select one or more First Honor Awards for Distinguished Accomplishments in Architecture, and Awards of Merit in Architecture for as many exhibits as the jury deems deserving.

Announcement of the winners will be made during National Library Week, April 21-27. 